Article

\title{
Juvenile Arthritis Patients Suffering from Chronic Inflammation Have Increased Activity of Both IDO and GTP-CH1 Pathways But Decreased BH4 Efficacy: Implications for Well-Being, Including Fatigue, Cognitive Impairment, Anxiety, and Depression
}

\author{
Gerdien A. H. Korte-Bouws ${ }^{1}$, Eline Albers ${ }^{1}$, Marije Voskamp ${ }^{1}$, Hendrikus Hendriksen ${ }^{1}$, \\ Lidewij R. de Leeuw ${ }^{1}$, Onur Güntürkün ${ }^{2}$, Sytze de Roock ${ }^{3}$, Sebastiaan J. Vastert ${ }^{3}$ and \\ S. Mechiel Korte ${ }^{1,2, *(\mathbb{D})}$ \\ 1 Division of Pharmacology, Utrecht Institute for Pharmaceutical Sciences (UIPS), Utrecht University, \\ Faculty of Science, Universities 99, 3584 CG Utrecht, The Netherlands; G.A.H.Korte@uu.nl (G.A.H.K.-B.); \\ e.g.albers@students.uu.nl (E.A.); m.j.voskamp@students.uu.nl (M.V.); H.Hendriksen@uu.nl (H.H.); \\ l.r.deleeuw@uu.nl (L.R.d.L.) \\ 2 Department of Biopsychology, Faculty of Psychology, Ruhr-Universität Bochum, Universitätsstraße 150, \\ D-44780 Bochum, Germany; onur.guentuerkuen@ruhr-uni-bochum.de \\ 3 Paediatric Rheumatology, Wilhelmina Children's Hospital, University Medical Center Utrecht, Lundlaan 6, \\ 3584 EA Utrecht, The Netherlands; S.deRoock@umcutrecht.nl (S.d.R.); B.Vastert@umcutrecht.nl (S.J.V.) \\ * Correspondence: Sijmen.Korte@rub.de or S.M.Korte@uu.nl; Tel.: +31-302-537-353
}

Received: 20 November 2018; Accepted: 29 December 2018; Published: 8 January 2019

\begin{abstract}
Juvenile idiopathic arthritis (JIA) represents joint inflammation with an unknown cause that starts before the age of 16 , resulting in stiff and painful joints. In addition, JIA patients often report symptoms of sickness behavior. Recent animal studies suggest that proinflammatory cytokines produce sickness behavior by increasing the activity of indoleamine-2,3-dioxygenase (IDO) and guanosinetriphosphate-cyclohydrolase-1 (GTP-CH1). Here, it is hypothesized that inflammation in JIA patients enhances the enzymatic activity of IDO and GTP-CH1 and decreases the co-factor tetrahydrobiopterin (BH4). These compounds play a crucial role in the synthesis and metabolism of neurotransmitters. The aim of our study was to reveal whether inflammation affects both the GTP-CH1 and IDO pathway in JIA patients. Serum samples were collected from twenty-four JIA patients. In these samples, the concentrations of tryptophan (TRP), kynurenine $(\mathrm{KYN})$, tyrosine (TYR), neopterin, and phenylalanine (PHE) were measured. An HPLC method with electrochemical detection was developed to quantify tryptophan, kynurenine, and tyrosine. Neopterin and phenylalanine were quantified by ELISA. The KYN/TRP ratio was measured as an index of IDO activity, while the PHE/TYR ratio was measured as an index of BH4 activity. Neopterin concentrations were used as an indirect measure of GTP-CH1 activity. JIA patients with high disease activity showed higher levels of both neopterin and kynurenine, and a higher ratio of both KYN/TRP and PHE/TYR and lower tryptophan levels than clinically inactive patients. Altogether, these data support our hypothesis that inflammation increases the enzymatic activity of both IDO and GTP-CH1 but decreases the efficacy of the co-factor $\mathrm{BH} 4$. In the future, animal studies are needed to investigate whether inflammation-induced changes in these enzymatic pathways and co-factor BH4 lower the levels of the brain neurotransmitters glutamate, noradrenaline, dopamine, serotonin, and melatonin, and consequently, whether they may affect fatigue, cognition, anxiety, and depression. Understanding of these complex neuroimmune interactions provides new possibilities for Pharma-Food interventions to improve the quality of life of patients suffering from chronic inflammation.
\end{abstract}


Keywords: arthritis; inflammation; sickness behavior; fatigue; biomarkers; indoleamine-2,3dioxygenase (IDO); guanosinetriphosphate-cyclohydrolase-1 (GTP-CH1); tetrahydrobiopterin (BH4); tryptophan; kynurenine; tyrosine; neopterin; phenylalanine

\section{Introduction}

Juvenile idiopathic arthritis (JIA) is a chronic inflammatory disease that has an onset before the age of 16 and is characterized by periods of disease flares [1]. The core symptoms of JIA are pain, swelling, stiffness, fever, rash, and limping [2]. JIA can affect one joint or many, and while some patients experience these symptoms for only a short period of time, others can suffer from JIA their whole lives [2].

Remarkably, a quarter of the JIA patients suffer from severe fatigue, and they prioritize fatigue within their main problems [3,4]. Fatigue, which is a core symptom of sickness behavior, is reported by patients as extreme, overwhelming, unremitting, and unrelated to physical activity [4-6]. Unfortunately, fatigue is difficult to evaluate and quantify because of its subjective nature and varied appearances (e.g., cognitive, sleep/rest, physical, emotional) [4-7]. In inflammatory disorders, central fatigue is often observed that comprises several dimensions, namely physical fatigue (i.e., reduced performance in physical tasks), mental fatigue (i.e., reduced performance in cognitive tasks), and the lack of motivation (i.e., reduced effort to obtain hedonic reward) [8]. Therefore, it is not surprising that JIA patients suffering from central fatigue report it as under-recognized and rarely treated [5].

Next to fatigue, more brain-related symptoms may develop. In the long term, arthritis patients often have inflammation-induced cognitive impairments [9]. Furthermore, in children with JIA, a significantly higher rate of anxiety and depression can be observed compared to a healthy control group [10].

Remarkably, a multi-modal MRI study in rheumatoid arthritis (RA) patients showed that high levels of inflammation were associated with more connections between the inferior parietal lobule (IPL), medial prefrontal cortex, and multiple brain networks (including the dorsal attention network, salience network, and medial visual network), as well as reduced IPL grey matter. These patterns of connectivity predicted fatigue, pain, and cognitive dysfunction [11].

Most recently, a review in the journal The Lancet discussing the link between inflammation and the comorbidity of rheumatoid arthritis and depression [12] showed that psychoneuroimmunology research is finally being taken seriously, and that it has arrived in the domain of the medical world.

Coming from studying disparate disorders, i.e., immune diseases and brain disorders, elements that were previously considered to be domains of one discipline are now discovered in the other. There is a rapidly growing amount of evidence demonstrating a strong bidirectional signaling between the immune system and the brain. For example, a proinflammatory response, characterized by high blood levels of the following cytokines: TNF- $\alpha$; IL-1; and IL-6 [13], affects monoamine neurotransmitter systems to induce sickness behavior [14,15], including the core symptom of fatigue [4]. In agreement, proinflammatory conditions during rheumatoid arthritis (RA), multiple sclerosis (MS), and even cancer go hand in hand with fatigue, cognitive impairment, and depressive symptoms $[4,16,17]$. In agreement, it has been reported that depression and fatigue are often associated with increased levels of proinflammatory cytokines [18,19].

Previously, a strong relation between fatigue and pain was shown in JIA patients, which was the strongest for females [3]. The relationship between inflammatory activity and disease activity was less clear [20,21]. Although some biologicals have beneficial effects on fatigue, often a large part of the fatigue remains [4,21]. Sometimes, paradoxical drug effects can be observed. For example, it has been reported that the immunosuppressant methotrexate (MTX) produced less fatigue in patients with rheumatoid arthritis [21], but more fatigue was observed after MTX treatment in another study [22]. 
These unclear and inconsistent data leave a perfect opportunity for us to gain more knowledge on the relationship between inflammation, disease activity, and possible alterations in enzymatic activity of indoleamine-2,3-dioxygenase (IDO) and guanosinetriphosphate-cyclohydrolase-1 (GTP-CH1), which are involved in the synthesis of neurotransmitters. Previously, it was shown that a chronic low-grade inflammation in elderly people was associated with altered tryptophan and tyrosine metabolism, which was suggested to be involved in disturbed mental well-being [23]. Remarkably, the same study showed that inflammation was correlated with higher levels of both neopterin and kynurenine, lower levels of tryptophan, and a higher KYN/TRP ratio [23]. In the present study, we hypothesize that increased chronic inflammation affects the biosynthesis and metabolism of neurotransmitters, which may have consequences for well-being, including fatigue, cognition, anxiety, and depression.

Therefore, in the present study, several precursors and amino acids are measured as a reflection of enzyme activity and co-factor BH4 efficacy. To this end, concentrations of neopterin, kynurenine, tryptophan, tyrosine, and phenylalanine were measured in the serum of JIA patients who have high disease activity or are clinically inactive and receive MTX or no drug treatment.

\section{Results}

\subsection{Disease Activity and MTX Treatment}

The disease activity of the participants was classified according to the clinical juvenile arthritis disease activity score (cJADAS). Clinically inactive (IA) patients were defined as cJADAS $<0.5$, whereas high disease activity (HDA) was set at cJADAS $\geq 10.0$. (see Table 1 ). The corresponding C-reactive protein (CRP) values were in line with the disease activity scores. Remarkably, MTX treatment significantly $(p<0.01)$ lowered CRP levels during high disease activity, while the cJADAS score was not significantly reduced but was still significantly higher $(p<0.05)$ than that of clinically inactive patients. There were neither significant effects of being male or female nor of MTX-treatment on tryptophan (TRP), kynurenine (KYN), neopterin, phenylalanine (PHE), tyrosine (TYR), and the PHE/TYR ratio. Therefore, these data were pooled into two groups, more precisely, HDA $(n=12)$ and IA $(n=12)$, except for the KYN/TRP ratio during high disease activity (HDA), because MTX treatment lowered it significantly $(p<0.05)$.

Table 1. The juvenile idiopathic arthritis (JIA) patients were divided into four groups based on disease activity and methotrexate (MTX) use. Data are presented as means \pm SEM. Significance is described as ${ }^{*} p<0.05$ for comparison of high disease activity versus clinically inactive and ${ }^{\#} p<0.05$ for comparison of high disease activity without MTX versus high disease activity with MTX.

\begin{tabular}{ccccc}
\hline $\begin{array}{c}\text { DISEASE } \\
\text { ACTIVITY }\end{array}$ & $\begin{array}{c}\text { High Disease } \\
\text { Activity (HDA) }\end{array}$ & $\begin{array}{c}\text { High Disease } \\
\text { Activity (HDA) }\end{array}$ & $\begin{array}{c}\text { Clinically Inactive } \\
\text { (IA) }\end{array}$ & $\begin{array}{c}\text { Clinically Inactive } \\
\text { (IA) }\end{array}$ \\
\hline MTX & No & Yes & No & Yes \\
\hline CJADAS & $18.7 \pm 2.5^{*}$ & $14.3 \pm 0.4^{*}$ & 0 & 0 \\
CRP & $90.2 \pm 38.8^{*}$ & $31.8 \pm 10.6^{*}$ & $0.3 \pm 0.1$ & $0.1 \pm 0.1$ \\
VAS & $4.98 \pm 1.26^{*}$ & $6,82 \pm 0.9^{*}$ & $0.0 \pm 0.0$ & $0.08 \pm 0.04$ \\
\hline
\end{tabular}

\subsection{GTP-CH1 Activity}

\subsubsection{Neopterin}

Neopterin concentrations in the high disease activity (HDA) JIA group were significantly higher $(p<0.01)$ compared to levels in clinically inactive (IA) patients (see Figure 1$)$. 


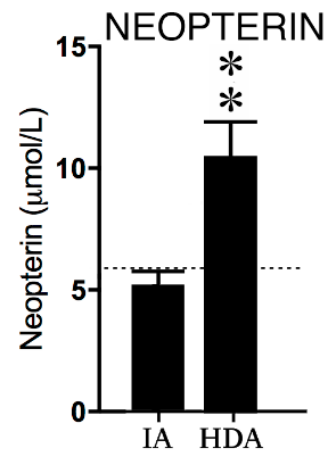

Figure 1. Neopterin concentrations in clinically inactive patients (IA) $(n=12)$ and high disease activity (HDA) $(n=12)$. The dotted line is the reference value in healthy children from previous studies [24-26]. Data are presented as means \pm SEM. Significance is described as ${ }^{* *} p<0.01$.

\subsubsection{Phenylalanine and Tyrosine}

Disease activity affected neither phenylalanine (PHE) nor tyrosine (TYR) concentrations; however, the PHE/TYR ratio was significantly $(p<0.01)$ increased in the high disease activity (HDA) group compared to the clinically inactive (IA) group (see Figure 2) The lower reference values of PHE concentrations in healthy children suggest increased PHE levels in both the IA and HDA group.
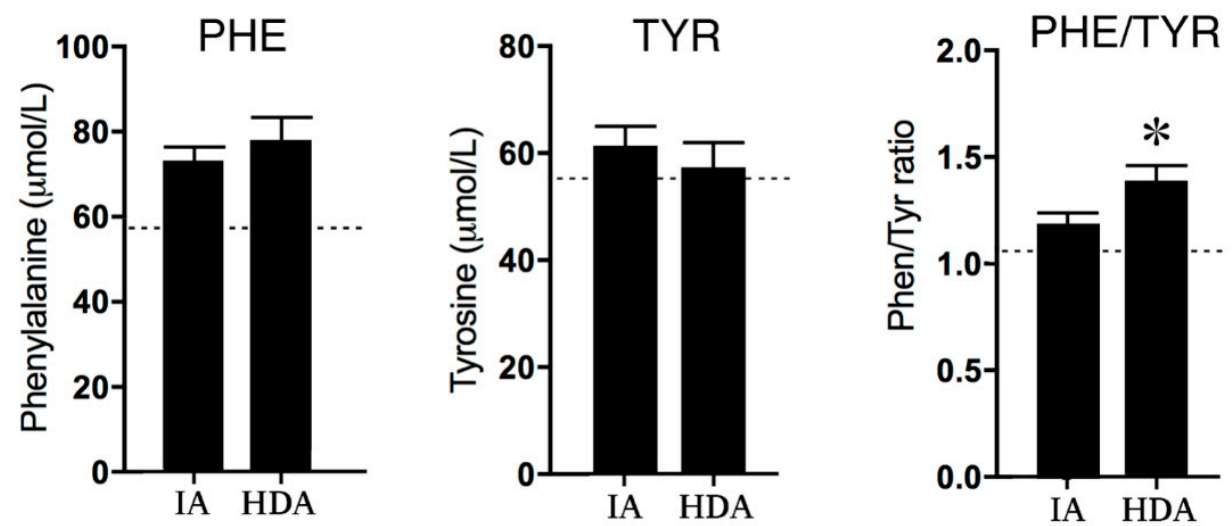

Figure 2. Phenylalanine (PHE) and Tyrosine (TYR) concentrations and the PHE/TYR ratio in clinically inactive patients (IA) $(n=12)$ and high disease activity (HDA) $(n=12)$. The dotted lines are the reference values in healthy children from previous studies [24-26]. Data are presented as means \pm SEM. Significance is described as ${ }^{*} p<0.05$.

\subsection{IDO Activity}

\subsubsection{Kynurenine and Tryptophan}

Tryptophan (TRP) concentrations in the high disease activity (HDA) group were significantly $(p<0.01)$ lower than in clinically inactive (IA) patients. Consequently, the KYN/TRP ratio was significantly $(p<0.05)$ increased in the HDA group compared to the IA group. The lower reference values of KYN concentrations in healthy children suggest increased KYN levels in both the IA and HDA group (see Figure 3). 

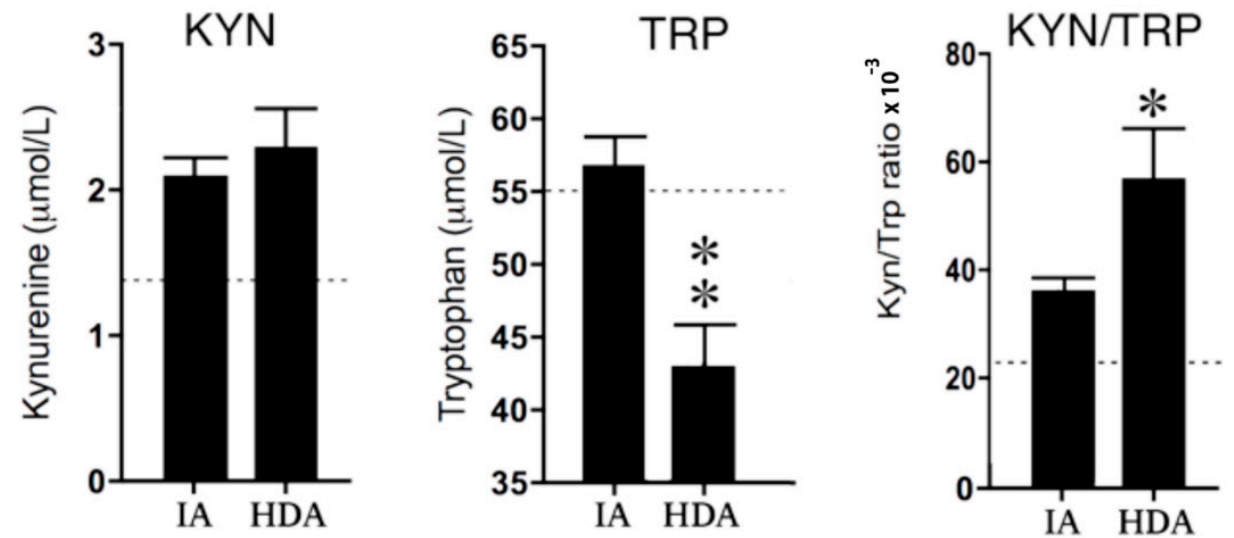

Figure 3. Kynurenine $(K Y N)$ and tryptophan (TRP) concentrations and the KYN/TRP ratio $\times 10^{-3}$ in clinically inactive patients (IA) $(n=12)$ and high disease activity (HDA) $(n=12)$. The dotted lines are the reference values in healthy children from previous studies used [24-26]. Data are presented as means \pm SEM. Significance is described as ${ }^{*} p<0.05$ and ${ }^{* *} p<0.01$.

\subsubsection{Kynurenine, Tryptophan, and MTX Treatment}

Remarkably, MTX did not affect the KYN/TRP ratio in the IA group, but MTX significantly $(p<0.05)$ decreased the KYN/TRP ratio in the HDA group (see Figure 4). Nevertheless, the lower reference values of KYN/TRP ratio in all groups suggests increased KYN/TRP ratios in both the IA and HDA group (see Figure 4).
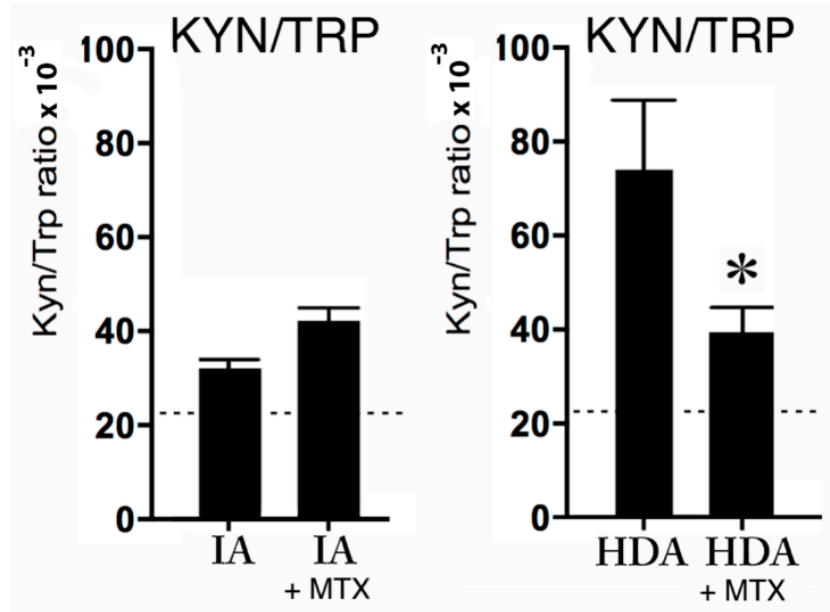

Figure 4. The KYN/TRP ratio $\times 10^{-3}$ in clinically inactive patients (IA) without $(n=6)$ or with MTX treatment $(n=6)$, and the KYN/TRP ratio $\times 10^{-3}$ during high disease activity (HDA) $(n=6)$ without or with MTX treatment $(n=6)$. The dotted lines are the reference values in healthy children from previous studies [24-26]. Data are presented as means \pm SEM. Significance is described as * $p<0.05$.

\section{Discussion}

As hypothesized, the present study clearly showed that JIA patients with high disease activity had higher levels of neopterin but lower levels of tryptophan and a higher ratio of both KYN/TRP and PHE/TYR than clinically inactive JIA patients. This is in agreement with the hypothesis that inflammation increases the enzymatic activity of both IDO and GTP-CH1 and decreases the efficacy of the co-factor BH4. Interestingly, these affected enzymatic pathways, and co-factor BH4, play a critical role in the synthesis of the brain neurotransmitters noradrenaline, dopamine, serotonin, melatonin, and glutamate, which are known for their role in mental health problems, including fatigue, cognition, anxiety, and depression. Therefore, it is not surprising that JIA patients with high disease activity have 
decreased well-being. In Figure 5, we present the hypothetical construct of how proinflammatory cytokines affect the brain.

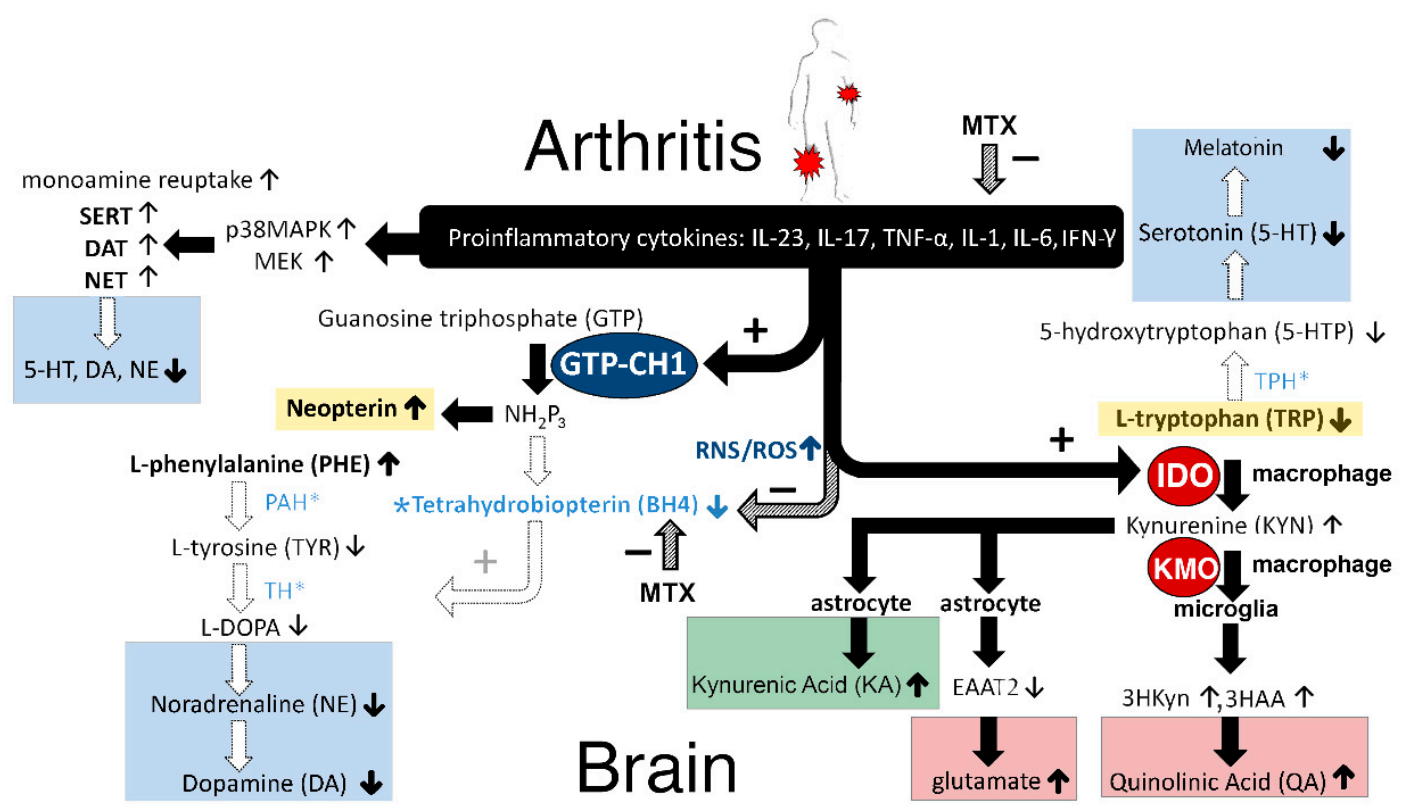

Figure 5. Hypothetical construct of how proinflammatory cytokines affect neurotransmitters in the brain (explanation of the figure can be found in the Discussion section).

\subsection{GTP-CH1 Pathway}

\subsubsection{Neopterin}

As expected, the present study shows that neopterin levels are significantly increased in JIA patients with high disease activity (cJADAS) compared to clinically inactive JIA patients. This is in line with earlier findings of Abu Shady and co-workers, showing a significant positive correlation between serum neopterin and the erythrocyte sedimentation rate (ESR), TNF- $\alpha$, IL-6, monocyte chemoattractant protein-1 (MCP-1), and disease activity as measured by JADAS-27 [27]. It was shown that both serum neopterin levels and JADAS-27 reflected disease activity in JIA. In agreement, in rheumatoid arthritis (RA) patients, a significant positive correlation between neopterin levels and disease activity was observed [28]. Similar observations have been made in patients with Crohn's disease [29] and ulcerative colitis [30]. Thus, the biomarker neopterin is not specific for arthritis. In agreement, high neopterin (6-D-trihydroxypropyl-pterin) levels have been observed during inflammation and/or autoimmunity, aging ( $>80$ year), bacterial, viral, and parasite infections, rejection episodes after allograft transplantation, and several malignant tumor diseases [31].

There is general agreement that neopterin levels reflect the activity of the cellular immune system [31]. This can be explained as follows (see Figure 5): Activated T-helper 1 (Th1) lymphocytes produce so-called lymphokines, such as interferon-gamma (IFN- $\gamma$ ) [32], which in macrophages and dendritic cells stimulates the enzyme guanosine triphosphate-cyclohydrolase 1 (GTP-CH1) [33,34] (See Figure 5). Although tumor necrosis factor- $\alpha$ (TNF- $\alpha$ ) does not directly stimulate GTP-CH1, it may enhance the sensitivity of macrophages to IFN- $\gamma$, and therefore further increase the activity of the GTP-CH1 pathway [35]. Consequently, 7,8-dihydroneopterin-triphosphate (NH2P3) is formed as an intermediate from GTP by GTP-CH1 [36]. Remarkably, there is almost no biopterin-forming enzyme pyruvoyl-tetrahydropterin synthase (PTPS) present in human macrophages and monocytes, in contrast to brain cells, and therefore, $\mathrm{NH} 2 \mathrm{P} 3$ is largely used for neopterin synthesis and release by the activated immune system [36], at the expense of the synthesis of BH4 by other cells [37]. 
There is a growing body of evidence that neopterin is not only a biomarker of Th1-cellular immune activity, but neopterin also plays an important role in host-defense reactions [38]. Activation of monocytes and macrophages increases the production of reactive oxygen and nitrogen species (ROS/RNS). It has been suggested that neopterin amplifies the cytotoxic forces of ROS/RNS directed against invading pathogens, and it increases oxidative stress during immune activation [38].

\subsubsection{Tetrahydrobiopterin (BH4)}

The higher PHE/TYR ratio in high disease activity JIA patients was in accordance with our hypothesis and supports the notion that increased inflammation in JIA patients lowered BH4 activity, which is also corroborated by higher neopterin levels. This is in agreement with earlier findings in elderly persons with chronic low-grade inflammation that inflammation was associated with increases in phenylalanine concentrations at the expense of tyrosine [23]. Furthermore, this study showed that a higher PHE/TYR ratio was correlated more with neurovegetative symptoms, including sleep disturbance, digestive symptoms, fatigue, sickness, and motor symptoms [23] (see Figure 6).

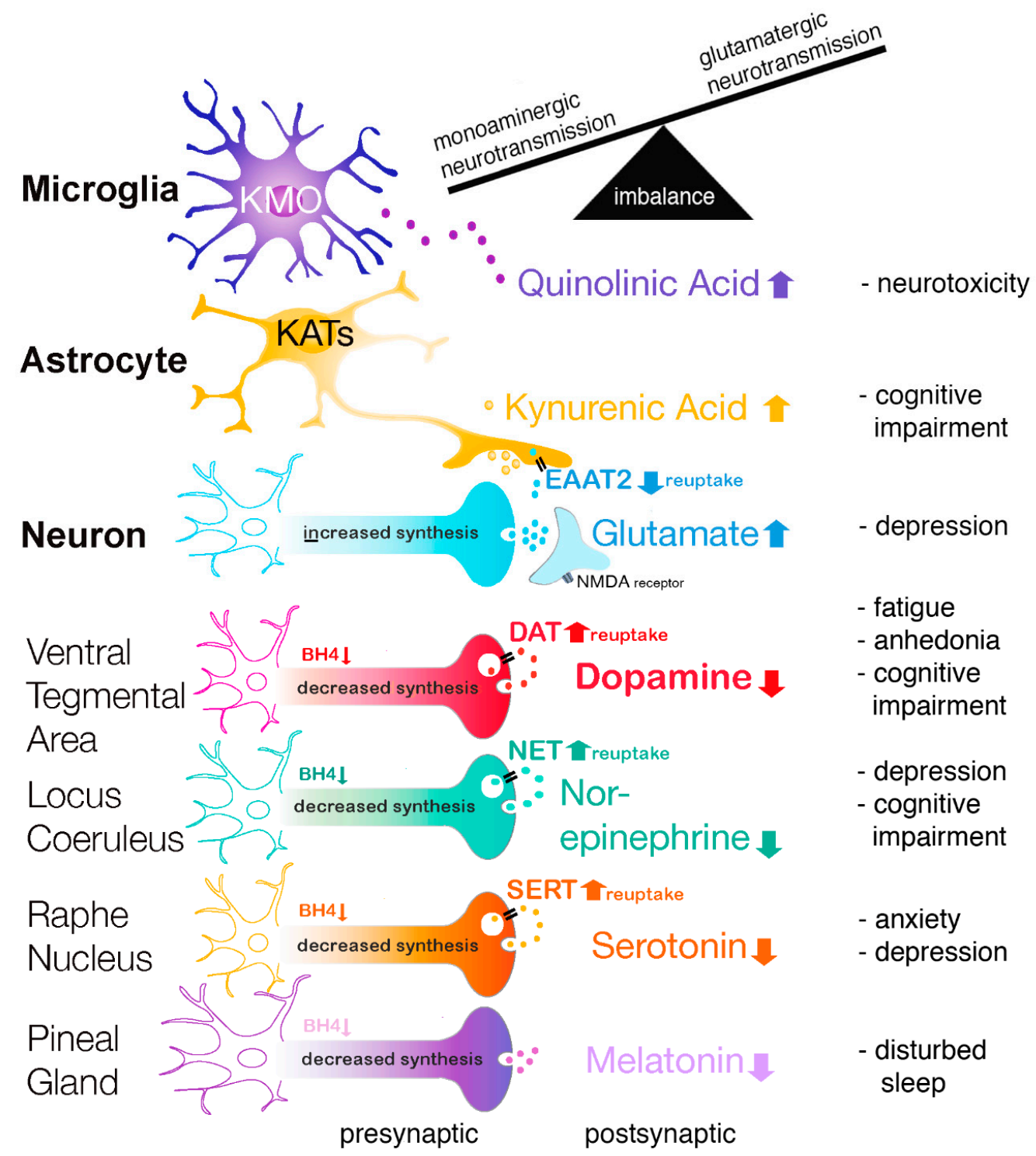

Figure 6. Relation between inflammation, neurotransmitter imbalance, and brain disorders.

The above described findings in JIA patients can be explained as follows: Levels of BH4 drop despite the inflammation-induced increase in GTP-CH1, which is the rate-limiting enzyme for the 
biosynthesis of $\mathrm{BH} 4$ from guanosine triphosphate (GTP), because NH2P3 is largely used for neopterin synthesis at the expense of the synthesis of BH4 [31,39]. Since JIA patients have more oxidative and nitrosative stress [40] in the presynaptic neurons, the highly redox-sensitive $\mathrm{BH} 4$ can easily be oxidized to the inactive dihydrobiopterin (BH2) [41] due to inflammation-induced increases in nitric oxide synthases (NOS), ROS, and RNS [17,39,42-44].

Importantly, $\mathrm{BH} 4$ is a crucial co-factor for several rate-limiting enzymes to synthesize different monoamine neurotransmitters [10]. The BH4-influenced enzymes are: 1. Phenylalanine hydroxylase (PAH) for the conversion of L-Phenylalanine (PHE) to L-Tyrosine; 2. L-Tyrosine hydroxylase (TH) for the conversion of L-Tyrosine to 3,4-Dihydroxy-L-phenylalanine (L-DOPA) and followed by conversion to dopamine and to noradrenaline; 3. Tryptophan hydroxylase (TPH) for the conversion of L-Tryptophan (TRP) to 5-hydroxytryptophan (5-HTP). 5-HTP is further converted to serotonin [11], to n-acetyl-serotonin, and to melatonin; 4 . Nitric oxide synthases (NOS) produce nitric oxide (NO) by catalyzing a five-electron oxidation of a guanidino nitrogen of L-arginine [23,44,45]. Thus, in JIA patients, the oxidative and nitrosative stress (ROS/RNS) may ultimately lead to decreased BH4 availability and consequently, decreased serotonin, melatonin, dopamine, and noradrenaline levels. Especially, an inflammation-induced decrease in dopamine concentrations has been shown to be responsible for anhedonia and severe fatigue $[13,23]$ (see Figure 6). In agreement, it has been shown that the PHE/TYR ratio was associated with fatigue and was negatively correlated with cerebrospinal fluid dopamine concentrations [8]. Furthermore, imaging studies in patients suggest that inflammation produces mental fatigue because of lower dopaminergic neurotransmission in the cortico-striatal network, including the striatum and prefrontal cortex [15,21,46].

Interestingly, the folate antagonist MTX during high disease activity (HDA) significantly reduced the KYN/TRP ratio towards more normal values compared to HDA without MTX treatment (see Figure 4), probably via the lowering of both inflammation and IDO levels (see Figure 5, at the top). Following this reasoning, it was expected that MTX treatment could improve patients' overall mental health outcomes, because it is generally accepted that IDO levels are inversely correlated with serotonin levels. In contradiction (see Table 1), MTX treatment had a significantly worse effect on visual analogue scale (VAS) scores, when compared to HDA patients not treated with MTX. It is speculated that this apparent contradiction can be explained by the fact that MTX (like sulfasalazine) directly lowers the biosynthesis of BH4 (see Figure 5, in the midst). Consequently, MTX may attenuate the activities of the enzymes $\mathrm{PAH}, \mathrm{TH}$, and $\mathrm{TPH}$, resulting in lower noradrenaline, dopamine, and serotonin concentrations, respectively. These lower monoamine concentrations may explain why MTX itself can produce depressive-like symptoms and cognitive impairment, despite the inflammation-lowering effects [47].

\subsection{IDO Pathway}

\subsubsection{Tryptophan, Serotonin, and Melatonin}

The lower tryptophan concentration and the higher KYN/TRP ratio in JIA patients with high disease activity suggests an increase in tryptophan breakdown and therefore supports our hypothesis that the enzymatic activity of IDO is increased in JIA patients with an increased inflammatory state compared to clinically inactive JIA patients. Our results are in agreement with a study by Capuron and coworkers showing similar changes in tryptophan and tyrosine metabolism in sera of the elderly during chronic low-grade inflammation [23]. In accordance, it has been reported that upregulation of IDO also led to a decrease in the serotonin/tryptophan ratio in the bilateral hippocampus of mice suffering from arthritis [48]. In addition, during inflammation, increased IDO activity was associated with higher microglia activity in the brain $[49,50]$. Remarkably, it has been reported that elevated IDO activity can be observed in patients with depression as well as in rats suffering from anhedonia [51-53].

It is well known that altered serotonin levels are involved in aggression and impulsivity [54,55], sleep [56], anxiety [57], and mood disorders [58]. Normally, serotonin is used for the synthesis of 
melatonin in the pineal gland; therefore, lowered serotonin concentrations may result in reduced melatonin levels (see Figure 6). Since melatonin plays an important role in sleep regulation, this may explain why sleep can be disturbed in JIA patients [59].

\subsubsection{Kynurenine, Quinolinic Acid, and Glutamate}

Proinflammatory cytokines increase IDO activity and shunt tryptophan away from the serotonin route into the kynurenine route. Kynurenine, via different routes, is metabolized into either 3-hydroxykynurenine (3HKyn) and quinolinic acid (QA) in microglia or kynurenic acid (KA) in astrocytes $[25,60,61]$. Interestingly, Raison and co-workers found an association between IFN- $\alpha$-induced synthesis of central kynurenine and QA in cerebrospinal fluid (CSF) and the development of depressive symptoms [61], whereas there was no such an association with KA [62,63].

Furthermore, 3HKyn generates free-radical species (including QA) that cause oxidative stress, while QA is also an N-Methyl-D-aspartate (NMDA) receptor agonist [64,65]. Thus, ROS/RNS may stimulate astrocytes to release glutamate and to inhibit glutamate transporters, especially excitatory amino acid transporter 2 (EAAT2) located on astrocytes [66,67]. Jointly, these actions result in increased glutamatergic neurotransmission [68] and potentially produce neurotoxic effects [69].

By contrast, during inflammation, KA may function as an NMDA receptor antagonist and, therefore, KA may have neuroprotective properties [70,71]. Surprisingly, endogenous KA has been shown to activate dopaminergic neurons in the rat ventral tegmental area through glutamatergic mechanisms [72]. Up to now, however, there has been no evidence that KA can compensate for the lower dopamine release due to decreased BH4 concentrations in patients. Furthermore, KA can suppress the prefrontal cortex (PFC) via presynaptic inhibition of $\alpha 7$-nicotinic acetylcholine receptor signaling, producing cognitive deficits (see Figure 6) [73].

\subsection{Increased Monoamine Reuptake}

Previously, it has been demonstrated that both lipopolysaccharides (LPS) and proinflammatory cytokines increase monoamine transporter (SERT, DAT, NET) trafficking and function [74-77]. There is a growing body of evidence that the influence of proinflammatory cytokines on SERT trafficking is p38 MAPK-dependent, resulting in increased SERT availability and more reuptake of serotonin [74-82]. Other kinases, however, may be associated with SERT regulation, such as Protein Kinase C (PKC), ERK1/2, phosphatidylinositol 3-Kinase/Akt, and adenosine [76,79,83]. In agreement, in humans, both in healthy adult women and psoriasis/psoriatic arthritis patients, a high correlation was observed between circulating inflammatory markers and brainstem SERT availability in humans. As expected, TNF- $\alpha$ inhibition with etanercept reduced this SERT availability [84]. More about immune activity and monoamine transporter function can be found in the present Special Issue of Pharmaceuticals [85].

\subsection{Pharma-Food Interventions}

\subsubsection{Inflammation and Immunosuppressants}

The first and most logic approach is the use of immunosuppressant drugs, since inflammation is the first link in the neuroimmune-cascade resulting in fatigue, cognitive impairment, and depressive symptoms (e.g., anhedonia), In agreement, TNF- $\alpha$ antibodies (e.g., infliximab) improve sleep quality [86] and depressive symptoms in patients with high baseline inflammatory biomarkers [87].

\subsubsection{Monoamines, Transporters, and Monoamine Reuptake Inhibitors}

Since inflammation increases the biological activity of monoamine transporters, the second approach is the use of specific serotonin reuptake inhibitors (SSRIs), serotonin norepinephrine reuptake inhibitors (SNRIs), and dopamine norepinephrine reuptake inhibitors (DNRIs) in order to restore the shortage of monoamines in the synaptic cleft [58]. 


\subsubsection{Monoamines, $\mathrm{BH} 4$, and Nutritional Interventions}

Regarding nutritional interventions, one has to be very critical because the European Food Safety Authority (EFSA) only awarded a few health claims of nutrition. Theoretically, one might expect positive effects of antioxidants (vitamin $C$ and vitamin $E$ ), because these supplements may reduce oxidative stress and therefore counteract the oxidation of $\mathrm{BH} 4$. In agreement, it has been suggested to use antioxidants to restore $\mathrm{BH} 4$ function in the treatment of inflammation-related cardiovascular disease [88,89].

Since the inflammation-induced reduction in BH4 levels may ultimately result in lower melatonin concentrations, the use of melatonin may counteract this deficit. In addition, melatonin is a powerful antioxidant. Therefore, it has been speculated that melatonin might protect $\mathrm{BH} 4$ from oxidation [90]. More research, however, is needed to investigate the role of melatonin in arthritis.

There are only analogues of BH4 commercially available that are very expensive. Therefore, they cannot be used as a general supplement. $\mathrm{BH} 4$ concentrations can alternatively be increased by nutritional interventions, such as the use of folate (B9-vitamin) and the biologically active metabolite 5-methyltetrahydrofolate (5-MTHF, L-methylfolate). They are involved in the re-methylation of homocysteine, creating methionine. The downstream metabolite of methionine is S-adenosylmethionine (SAMe), which is also a methyl donor that stimulates the synthesis of BH4. Therefore, folate, L-methylfolate, and SAMe can be used to counteract the inflammation-induced decrease in BH4. In agreement, there is a growing body of evidence that L-methylfolate and SAMe supplementation might improve antidepressant actions of SSRIs in patients, who normally tend not to respond well to SSRI drugs $[65,91,92]$.

\subsubsection{Glutamate and Nutritional Interventions}

Inflammation and chronic stress increase glutamatergic neurotransmission $[65,93]$ but decrease expression of brain-derived neurotrophic factor (BDNF) in limbic structures [94] and consequently alter dendritic remodeling in subareas of PFC, the amygdala, and the hippocampus, decrease the number of hippocampal dendritic spines and decrease dentate gyrus neurogenesis (for review: See Reference [95]). Interactions between the corticosteroid (their receptors) and glutamate systems play a pivotal role in the altered neuroplasticity and development of mental disorders [95]. Recently, in a chronic stress animal model with sustained activation of neural mineralocorticoid receptors, it was reported that acetyl-L-carnitine (LAC), via an epigenetic mechanism (i.e., acetylation), induced mGlu2 receptors in the hippocampus and PFC $[96,97]$. Furthermore, LAC treatment normalized both glutamate overflow and increased BDNF expression [96-98]. Decreased plasma LAC levels have been observed in patients suffering from major depression, especially in those with stronger severity, earlier disease onset, and treatment-resistant depression [99]. In agreement, in animal models of depression, LAC leads to antidepressant-like responses after a few days of administration [96-98]. Therefore, it is speculated that LAC treatment, via normalizing glutamate overflow and BDNF expression, may have fast positive effects on the neuropsychiatric symptoms in juvenile arthritis patients.

Increased glutamatergic neurotransmission can also be normalized by a ketogenic diet. A ketogenic diet is a low-carb diet often with ketone bodies (acetoacetate and $\beta$-hydroxybuturate) or medium-length fatty acids generating ketone bodies. Ketone bodies are thought to inhibit mitochondrial production of ROS following glutamate excitotoxicity by increasing $\mathrm{NADH}$ oxidation [100]. A ketogenic diet has profound effects on multiple targets, including but not limited to, lowering glutamate- and increasing GABA transmission, and lowering oxidative stress [101]. Therefore, it is speculated that a ketogenic diet may also have positive effects on the supposed imbalance between monoamines and glutamate in the emotional brains of juvenile arthritis patients. 


\section{Materials and Methods}

\subsection{Study Population}

Twenty-four serum samples of anonymous children, between 8 and 18 years of age, which were diagnosed with JIA were collected. All participants were diagnosed with JIA. Disease activity was displayed by the clinical juvenile arthritis disease activity score (cJADAS). The cJADAS is constructed around three elements: The active joint count (AJC), physician global assessment (PGA), and parent/patient visual analogue scale (VAS) of well-being [102]. In more detail, the parent/patient is asked to make a global assessment of the child's overall well-being on a $10 \mathrm{~cm}$ visual analogue scale, with anchors of ' $0=$ very good' and ' $10=$ very poor'. The cJADAS score has shown to be a very useful tool to identify JIA patients with high disease activity in need of anti-TNF therapy [103].

The Medical Ethics Committee (METC) of the Utrecht University Medical Centre (UUMC), the Netherlands, approved the present study, as part of project PharmaChild METC number 11-499/C.

Fifteen participants were female $(62.5 \%)$ and nine participants $(37.5 \%)$ were male. Patients were grouped based on disease activity (high disease activity (i.e., cJADAS $\geq 10.0$ ) or clinically inactive (i.e., cJADAS <0.5). The corresponding CRP values were in line with the disease activity scores. Half of the patients were treated with MTX; the other half of the patients did not use any immunosuppressants. Since there was no difference in disease activity between male and female participants, the JIA-patients were divided in four groups ( $n=6$ per group) based on disease activity and MTX use (see Table 1 ).

\subsection{Blood Samples}

Blood samples for the measurement of tryptophan, tyrosine phenylalanine, kynurenine, and neopterin were stored at $-80^{\circ} \mathrm{C}$ at Wilhelmina Children's Hospital of University Medical Center Utrecht and two weeks before conductance of the assays moved to a lab freezer at $-20{ }^{\circ} \mathrm{C}$. Serum concentrations of neopterin and phenylalanine were measured by enzyme-linked immunosorbent assay (Tecan, Giessen, the Netherlands; and Immundiagnostik AG, Bensheim, Germany). Free tryptophan, tyrosine, and kynurenine serum concentrations were determined by high-performance liquid chromatography with electrochemical detection (Antec, vt-03 flow cell with ISAAC reference electrode). The potential of the detector was set at $0.9 \mathrm{~V}$. The column was a NeuroSep C18 (Antec, NeuroSep 115 C18, $1 \mathrm{~mm} \times 150 \mathrm{~mm}, 3 \mu \mathrm{m}$ particle size). The mobile phase consisted of 10\% Methanol, $50 \mathrm{mM}$ phosphate buffer $\mathrm{pH} 2.5,0.1 \mathrm{mM}$ EDTA, and $8 \mathrm{mM} \mathrm{KCl}$ and was pumped at $50 \mu \mathrm{L} / \mathrm{min}$ through the column. The autosampler temperature was set at $8^{\circ} \mathrm{C}$ degrees. To serum samples, methyldopa was added as internal standard. The samples were deproteinated using perchloric acid, centrifuged, and the supernatant was mixed with potassium acetate (equimolar to perchloric acid) to reduce acidity. The samples were centrifuged once more to remove the precipitate and the supernatant was diluted eight times with ultra-pure water. A total of $5 \mu \mathrm{L}$ was subsequently injected. Calibration curve samples and quality control samples were prepared in bovine serum albumin solution and pretreated and analyzed as described for serum samples. Precision (rsd) and accuracy (deviation from actual concentration) of the method were below $10 \%$ for all analytes and calibration curve concentrations. The ratios of KYN/TRP and Phe/TYR were used as indexes of, respectively, IDO activity and GTP-CH1 activity.

\subsection{Statistics}

All neopterin and phenylalanine concentrations were measured in threefold. In two participants, one of the three neopterin measurements was not considered for data analyses, because these were completely out of range and therefore treated as outliers. No missing values for tryptophan, tyrosine, and kynurenine were obtained. Concentrations of biological markers were compared between the two groups, i.e., clinically inactive patients (IA) and high disease activity (HDA), with the independent samples $t$-test. Last, Bonferroni's post hoc analysis was used to compare the biological markers across the four subgroups (see Table 1: IA; HDA; without MTX; and with MTX). As a reference group, 
concentrations of biomarkers of healthy children from previous studies were used [24-26]. These were only used as a rough indication and were not used for statistics, because both age and gender distribution differed from our JIA patients. All statistical analyses were performed with SPSS21. Data are presented as means \pm SEM. The significance level for all tests was set a $p<0.05$.

\section{Conclusions}

JIA patients with high disease activity are characterized by higher serum levels of both neopterin and kynurenine, and a higher ratio of both KYN/TRP and PHE/TYR and lower tryptophan serum levels than in clinically inactive JIA patients, reflecting increased activity of both IDO and GTP-CH1 pathways but decreased BH4 efficacy during chronic inflammation. Here, it is hypothesized that this may produce an imbalance between glutamate and monoamines with negative implications for well-being, including fatigue, cognition, anxiety, and depression.

Author Contributions: Data curation, E.A., M.V., and L.R.d.L.; Formal analysis, E.A. and G.A.H.K.-B.; Funding acquisition, S.M.K., S.J.V., and O.G.; Investigation, S.d.R. and S.J.V.; Methodology, E.A. and G.A.H.K.-B.; Project administration, E.A. and S.d.R.; Resources, S.M.K., S.J.V. and O.G.; Supervision, S.M.K. and G.A.H.K.-B.; Validation; Writing—original draft, E.A. and G.A.H.K.-B.; Writing—review and editing, O.G., H.H., and S.M.K.

Funding: This study was financially supported by: "Future Food Utrecht" of Utrecht University, the Netherlands; "The Dutch Arthritis Society" (ReumaNederland, formerly known as Reumafonds) project 17-1-101; and “Die Deutsche Forschungsgemeinschaft (DFG)" through SFB 1280.

Conflicts of Interest: The authors declare no conflict of interest.

\section{References}

1. Ravelli, A.; Martini, A. Juvenile idiopathic arthritis. Lancet 2007, 369, 767-778. [CrossRef]

2. Laxer, R.M.; Sherry, D.D.; Hashkes, P.J. Juvenile Idiopathic Arthritis (JIA). In Pediatric Rheumatology in Clinical Practice; Springer: Cham, Switzerland, 2016; pp. 31-62.

3. Nijhof, L.N.; van de Putte, E.M.; Wulffraat, N.M.; Nijhof, S.L. Prevalence of severe fatigue among adolescents with pediatric rheumatic diseases. Arthritis Care Res. 2016, 68, 108-114. [CrossRef] [PubMed]

4. Norheim, K.B.; Jonsson, G.; Omdal, R. Biological mechanisms of chronic fatigue. Rheumatology 2011, 50, 1009-1018. [CrossRef] [PubMed]

5. Hewlett, S.; Cockshott, Z.; Byron, M.; Kitchen, K.; Tipler, S.; Pope, D.; Hehir, M. Patients' perceptions of fatigue in rheumatoid arthritis, Overwhelming, uncontrollable, ignored. Arthritis Rheum.-Arthritis Care Res. 2005, 53, 697-702. [CrossRef] [PubMed]

6. Repping-Wuts, H.; Uitterhoeve, R.; van Riel, P.; van Achterberg, T. Fatigue as experienced by patients with rheumatoid arthritis (RA), A qualitative study. Int. J. Nurs. Stud. 2008, 45, 995-1002. [CrossRef] [PubMed]

7. Hewlett, S.; Chalder, T.; Choy, E.; Cramp, F.; Davis, B.; Dures, E.; Nicholls, C.; Kirwan, J. Fatigue in rheumatoid arthritis, time for a conceptual model. Rheumatology 2011, 50, 1004-1006. [CrossRef] [PubMed]

8. Karshikoff, B.; Sundelin, T.; Lasselin, J. Role of inflammation in human fatigue: Relevance of multidimensional assessments and potential neuronal mechanisms. Front. Immunol. 2017, 8, 1-12. [CrossRef]

9. Petersen, L.E.; Baptista, T.S.A.; Molina, J.K.; Motta, J.G.; do Prado, A.; Piovesan, D.M.; de Nardi, T.; Viola, T.W.; Vieira, É.L.M.; Teixeira, A.L.; et al. Cognitive impairment in rheumatoid arthritis: Role of lymphocyte subsets, cytokines and neurotrophic factors. Clin. Rheumatol. 2018, 37, 1171-1181. [CrossRef]

10. Memari, A.H.; Chamanara, E.; Ziaee, V.; Kordi, R.; Raeeskarami, S.R. Behavioral Problems in Juvenile Idiopathic Arthritis: A Controlled Study to Examine the Risk of Psychopathology in a Chronic Pediatric Disorder. Int. J. Chronic Dis. 2016, 2016, 5726236. [CrossRef]

11. Schrepf, A.; Kaplan, C.M.; Ichesco, E.; Larkin, T.; Harte, S.E.; Harris, R.E.; Murray, A.D.; Waiter, G.D.; Clauw, D.J.; Basu, N. A multi-modal MRI study of the central response to inflammation in rheumatoid arthritis. Nat. Commun. 2018, 9, 2243. [CrossRef]

12. Nerurkar, L.; Siebert, S.; McInnes, I.B.; Cavanagh, J. Rheumatoid arthritis and depression: An inflammatory perspective. Lancet Psychiatry 2018. [CrossRef] 
13. Felger, J.C.; Li, L.; Marvar, P.J.; Woolwine, B.J.; Harrison, D.G.; Raison, C.L.; Miller, A.H. Tyrosine metabolism during interferon-alpha administration: Association with fatigue and CSF dopamine concentrations. Brain Behav. Immun. 2013, 31, 153-160. [CrossRef]

14. Dantzer, R.; Wollman, E.E.; Vitkovic, L.; Yirmiya, R. Cytokines, stress, and depression-Conclusions and perspectives. In Cytokines, Stress, and Depression; Dantzer, R., Wollman, E.E., Yirmiya, R., Eds.; Kluwer Academic/Plenum Publ: New York, NY, USA, 1999; pp. 317-329.

15. Felger, J.C.; Miller, A.H. Cytokine effects on the basal ganglia and dopamine function: The subcortical source of inflammatory malaise. Front. Neuroendocrinol. 2012, 33, 315-327. [CrossRef] [PubMed]

16. Bower, J.E. Cancer-related fatigue-mechanisms, risk factors, and treatments. Nat. Rev. Clin. Oncol. 2014, 11, 597-609. [CrossRef] [PubMed]

17. Morris, G.; Anderson, G.; Galecki, P.; Berk, M.; Maes, M.A. Narrative review on the similarities and dissimilarities between myalgic encephalomyelitis/chronic fatigue syndrome (ME/CFS) and sickness behavior. BMC Med. 2013, 11, 1-19. [CrossRef] [PubMed]

18. Maes, M.; Berk, M.; Goehler, L.; Song, C.; Anderson, G.; Gałecki, P.; Leonard, B. Depression and sickness behavior are Janus-faced responses to shared inflammatory pathways. BMC Med. 2012, 10, 1-19. [CrossRef] [PubMed]

19. Haroon, E.; Raison, C.L.; Miller, A.H. Psychoneuroimmunology Meets Neuropsychopharmacology: Translational implications of the impact of inflammation on Behavior. Neuropsychopharmacology 2012, 37, 137-162. [CrossRef]

20. Pollard, L.C.; Choy, E.H.; Gonzalez, J.; Khoshaba, B.; Scott, D.L. Fatigue in rheumatoid arthritis reflects pain, not disease activity. Rheumatology 2006, 45, 885-889. [CrossRef]

21. Van Hoogmoed, D.; Fransen, J.; Bleijenberg, G.; van Riel, P. Physical and psychosocial correlates of severe fatigue in rheumatoid arthritis. Rheumatology 2010, 49, 1294-1302. [CrossRef]

22. Butbul Aviel, Y.; Stremler, R.; Benseler, S.M.; Cameron, B.; Laxer, R.M.; Ota, S.; Schneider, R.; Spiegel, L.; Stinson, J.N.; Tse, S.M.; et al. Sleep and fatigue and the relationship to pain, disease activity and quality of life in juvenile idiopathic arthritis and juvenile dermatomyositis. Rheumatology 2011, 50, 2051-2060. [CrossRef]

23. Capuron, L.; Schroecksnadel, S.; Féart, C.; Aubert, A.; Higueret, D.; Barberger-Gateau, P.; Layé, S.; Fuchs, D. Chronic low-grade inflammation in elderly persons is associated with altered tryptophan and tyrosine metabolism: Role in neuropsychiatric symptoms. Biol. Psychiatry 2011, 70, 175-182. [CrossRef] [PubMed]

24. Satoh, T.; Brown, L.M.; Blattner, W.A.; Maloney, E.M.; Kurman, C.C.; Nelson, D.L.; Fuchs, D.; Wachter, H.; Tollerud, D.J. Serum neopterin, beta(2)-microglobulin, soluble interleukin-2 receptors, and immunoglobulin levels in healthy adolescents. Clin. Immunol. Immunopathol. 1998, 88, 176-182. [CrossRef] [PubMed]

25. Sweeten, T.; Milton, M.W.; Posey, D.J.; McDougle, C.J. Plasma Kynurenine Levels in Autistic Disorder. J. Dev. Phys. Dis. 2006, 18, 419-426. [CrossRef]

26. Bergwerff, C.E.; Luman, M.; Blom, H.J.; Oosterlaan, J. Paediatric reference values for total homocysteine, tryptophan, tyrosine and phenylalanine in blood spots. Scand. J. Clin. Lab. Investig. 2017, 77, 410-414. [CrossRef] [PubMed]

27. Shady, M.M.; Fathy, H.A.; Ali, A.; Youness, E.R.; Fathy, G.A. Association of neopterin as a marker of immune system activation and juvenile rheumatoid arthritis activity. J. Pediatr. 2015, 91, 352-357. [CrossRef] [PubMed]

28. Reibnegger, G.; Egg, D.; Fuchs, D.; Günther, R.; Hausen, A.; Werner, E.R.; Wachter, H. Urinary neopterin reflects clinical activity in patients with rheumatoid arthritis. Arthritis Rheum. 1986, 29, 1063-1070. [CrossRef] [PubMed]

29. Prior, C.; Bollbach, R.; Fuchs, D.; Hausen, A.; Judmaier, G.; Niederwieser, D.; Reibnegger, G.; Rotthauwe, H.W.; Werner, E.R.; Wachter, H. Urinary neopterin, a marker of clinical activity in patients with Crohn's disease. Clin. Chim. Acta 1986, 155, 11-21. [CrossRef]

30. Niederwieser, D.; Fuchs, D.; Hausen, A.; Judmaier, G.; Reibnegger, G.; Wachter, H.; Huber, C. Neopterin as a new biochemical marker in the clinical assessment of ulcerative colitis. Immunobiology 1985, 170, 320-326. [CrossRef]

31. Murr, C.; Widner, B.; Wirleitner, B.; Fuchs, D. Neopterin as a marker for immune system activation. Curr. Drug Metab. 2002, 3, 175-187. [CrossRef]

32. Schoenborn, J.R.; Wilson, C.B. Regulation of Interferon- $\gamma$ During Innate and Adaptive Immune Responses. Adv. Immunol. 2007, 96, 41-101. 
33. Schoedon, G.; Troppmair, J.; Adolf, G.; Huber, C.; Niederwieser, A. Interferon-gamma enhances biosynthesis of pterins in peripheral blood mononuclear cells by induction of GTP-cyclohydrolase I activity. J. Interferon Res. 1986, 6, 697-703. [CrossRef] [PubMed]

34. Huang, A.; Zhang, Y.-Y.; Chen, K.; Hatakeyama, K.; Keaney, J.F. Cytokine-Stimulated GTP Cyclohydrolase I Expression in Endothelial Cells Requires Coordinated Activation of Nuclear Factor-B and Stat1/Stat3. Circ. Res. 2005, 96, 164-171. [CrossRef] [PubMed]

35. Werner-Felmayer, G.; Werner, E.R.; Fuchs, D.; Hausen, A.; Reibnegger, G.; Wachter, H. Tetrahydrobiopterindependent Formation of Nitrite and Nitrate in Murine Fibroblasts. J. Exp. Med. 1990, 172, 1599-1607. [CrossRef] [PubMed]

36. Werner, E.R.; Werner-Felmayer, G.; Fuchs, D.; Hausen, A.; Reibnegger, G.; Yim, J.J.; Pfleiderer, W.; Wachter, H. Tetrahydrobiopterin biosynthetic activities in human macrophages, fibroblasts, THP-1, and T 24 cells. GTP-cyclohydrolase I is stimulated by interferon-gamma, and 6-pyruvoyl tetrahydropterin synthase and sepiapterin reductase are constitutively present. J. Biol. Chem. 1990, 265, 3189-3192. [PubMed]

37. Werner, E.R.; Werner-Felmayer, G.; Wachter, H. Tetrahydrobiopterin and cytokines. Proc. Soc. Exp. Biol. Med. 1993, 203, 1-12. [CrossRef]

38. Hoffmann, G.; Wirleitner, B.; Fuchs, D. Potential role of immune system activation-associated production of neopterin derivatives in humans. Inflamm. Res. 2003, 52, 313-321. [CrossRef]

39. Neurauter, G.; Schröcksnadel, K.; Scholl-Bürgi, S.; Sperner-Unterweger, B.; Schubert, C.; Ledochowski, M.; Fuchs, D. Chronic immune stimulation correlates with reduced phenylalanine turnover. Curr. Drug Metab. 2008, 9, 622-627. [CrossRef]

40. Lipińska, J.; Lipińska, S.; Stańczyk, J.; Sarniak, A.; Przymińska vel Prymont, A.; Kasielski, M.; Smolewska, E. Reactive oxygen species and serum antioxidant defense in juvenile idiopathic arthritis. Clin. Rheumatol. 2015, 34, 451-456. [CrossRef]

41. Landmesser, U.; Dikalov, S.; Price, S.R.; McCann, L.; Fukai, T.; Holland, S.M.; Mitch, W.E.; Harrison, D.G. Oxidation of tetrahydrobiopterin leads to uncoupling of endothelial cell nitric oxide synthase in hypertension. J. Clin. Investig. 2003, 111, 1201-1209. [CrossRef]

42. Kitagami, T.; Yamada, K.; Miura, H.; Hashimoto, R.; Nabeshima, T.; Ohta, T. Mechanism of systemically injected interferon-alpha impeding monoamine biosynthesis in rats: Role of nitric oxide as a signal crossing the blood-brain barrier. Brain Res. 2003, 978, 104-114. [CrossRef]

43. Zielasek, J.; Hartung, H.P. Molecular mechanisms of microglial activation. Adv. Neuroimmunol. 1996, 6, 191-222. [CrossRef]

44. Cunnington, C.; Channon, K.M. Tetrahydrobiopterin: Pleiotropic roles in cardiovascular pathophysiology. Heart 2010, 96, 1872-1877. [CrossRef] [PubMed]

45. Miller, A.H.; Haroon, E.; Raison, C.L.; Felger, J.C. Cytokine targets in the brain: Impact on Neurotransmitters and Neurocircuits. Depress. Anxiety 2013, 30, 297-306. [CrossRef] [PubMed]

46. Dobryakova, E.; DeLuca, J.; Genova, H.M.; Wylie, G.R. Neural correlates of cognitive fatigue: Cortico-striatal circuitry and effort-reward imbalance. J. Int. Neuropsychol. Soc. 2013, 19, 849-853. [CrossRef]

47. Yang, S.; Jan, Y.H.; Mishin, V.; Richardson, J.R.; Hossain, M.M.; Heindel, N.D.; Heck, D.E.; Laskin, D.L.; Laskin, J.D. Sulfa drugs inhibit sepiapterin reduction and chemical redox cycling by sepiapterin reductase. J. Pharmacol. Exp. Ther. 2015, 352, 529-540. [CrossRef]

48. Kim, H.; Chen, L.; Lim, G.; Sung, B.; Wang, S.; McCabe, M.F.; Rusanescu, G.; Yang, L.; Tian, Y.; Mao, J. Brain indoleamine 2,3-dioxygenase contributes to the comorbidity of pain and depression. J. Clin. Investig. 2012, 122, 2940-2954. [CrossRef]

49. Kwidzinski, E.; Bunse, J.; Aktas, O.; Richter, D.; Mutlu, L.; Zipp, F.; Nitsch, R.; Bechmann, I. Indolamine 2,3-dioxygenase is expressed in the CNS and down-regulates autoimmune inflammation. FASEB J. 2005, 19, 1347-1349. [CrossRef]

50. Corona, A.W.; Norden, D.M.; Skendelas, J.P.; Huang, Y.; O'Connor, J.C.; Lawson, M.; Dantzer, R.; Kelley, K.W.; Godbout, J.P. Indoleamine 2,3-dioxygenase inhibition attenuates lipopolysaccharide induced persistent microglial activation and depressive-like complications in fractalkine receptor (CX(3)CR1)-deficient mice. Brain Behav. Immun. 2013, 31, 134-142. [CrossRef]

51. Salazar, A.; Gonzalez-Rivera, B.L.; Redus, L.; Parrott, J.M.; O'Connor, J.C. Indoleamine 2,3-dioxygenase mediates anhedonia and anxiety-like behaviors caused by peripheral lipopolysaccharide immune challenge. Horm. Behav. 2012, 62, 202-209. [CrossRef] 
52. Dantzer, R.; O'Connor, J.C.; Lawson, M.A.; Kelley, K.W. Inflammation-associated depression: From serotonin to kynurenine. Psychoneuroendocrinology 2011, 36, 426-436. [CrossRef]

53. Leonard, B.; Maes, M. Mechanistic explanations how cell-mediated immune activation, inflammation and oxidative and nitrosative stress pathways and their sequels and concomitants play a role in the pathophysiology of unipolar depression. Neurosci. Biobehav. Rev. 2012, 36, 764-785. [CrossRef] [PubMed]

54. Wolf, D.; Klasen, M.; Eisner, P.; Zepf, F.D.; Zvyagintsev, M.; Palomero-Gallagher, N.; Weber, R.; Eisert, A.; Mathiak, K. Central serotonin modulates neural responses to virtual violent actions in emotion regulation networks. Brain Struct. Funct. 2018, 223, 3327-3345. [CrossRef] [PubMed]

55. Korte, S.M.; Prins, J.; Van den Bergh, F.S.; Oosting, R.S.; Dupree, R.; Korte-Bouws, G.A.H.; Westphal, K.G.; Olivier, B.; Denys, D.A.; Garland, A.; et al. The 5-HT(1A/1B)-receptor agonist eltoprazine increases both catecholamine release in the prefrontal cortex and dopamine release in the nucleus accumbens and decreases for reward and "waiting" impulsivity, but increases "stopping" impulsivity. Eur. J. Pharmacol. 2017, 794, 257-269. [CrossRef] [PubMed]

56. Hedlund, P.B.; Huitron-Resendiz, S.; Henriksen, S.J.; Sutcliffe, J.G. 5-HT7 Receptor Inhibition and Inactivation Induce Antidepressant-like Behavior and Sleep Pattern. Biol. Psychiatry 2005, 58, 831-837. [CrossRef] [PubMed]

57. Barf, T.; Korte, S.M.; Korte-Bouws, G.A.H.; Sonesson, C.; Damsma, G.; Bohus, B.; Wikström, H. Potential anxiolytic properties of R-(+)-8-OSO2CF3-PAT, a 5-HT 1A receptor agonist. Eur. J. Pharmacol. 1996, 297, 205-211. [CrossRef]

58. Korte, S.M.; Prins, J.; Krajnc, A.M.; Hendriksen, H.; Oosting, R.S.; Westphal, K.G.; Korte-Bouws, G.A.H.; Olivier, B. The many different faces of major depression: It is time for personalized medicine. Eur. J. Pharmacol. 2015, 753, 88-104. [CrossRef] [PubMed]

59. Stinson, J.N.; Hayden, J.A.; Ahola Kohut, S.; Soobiah, C.; Cartwright, J.; Weiss, S.K.; Witmans, M.B. Sleep problems and associated factors in children with juvenile idiopathic arthritis: A systematic review. Pediatr. Rheumatol. Online J. 2014, 12, 1-12. [CrossRef]

60. Chen, Y.; Brew, B.J.; Guillemin, G.J. Characterization of the kynurenine pathway in NSC-34 cell line: Implications for amyotrophic lateral sclerosis. J. Neurochem. 2011, 118, 816-825. [CrossRef]

61. Du, F.; Schmidt, W.; Okuno, E.; Kido, R.; Köhler, C.; Schwarcz, R. Localization of kynurenine aminotransferase immunoreactivity in the rat hippocampus. J. Comp. Neurol. 1992, 321, 477-487. [CrossRef]

62. Foster, A.C.; Collins, J.F.; Schwarcz, R. On the excitotoxic properties of quinolinic acid, 2,3-piperidine dicarboxylic acids and structurally related compounds. Neuropharmacology 1983, 22, 1331-1342. [CrossRef]

63. Guidetti, P.; Schwarcz, R. 3-Hydroxykynurenine potentiates quinolinate but not NMDA toxicity in the rat striatum. Eur. J. Neurosci. 1999, 11, 3857-6383. [CrossRef]

64. Lin, C.L.; Kong, Q.; Cuny, G.D.; Glicksman, M.A. Glutamate transporter EAAT2: A new target for the treatment of neurodegenerative diseases. Future Med. Chem. 2012, 4, 1689-1700. [CrossRef] [PubMed]

65. Haroon, E.; Miller, A.H.; Sanacora, G. Inflammation, Glutamate, and Glia: A Trio of Trouble in Mood Disorders. Neuropsychopharmacology 2017, 42, 193-215. [CrossRef] [PubMed]

66. Danbolt, N.C. Glutamate uptake. Prog. Neurobiol. 2001, 65, 100-105. [CrossRef]

67. Vercellino, M.; Merola, A.; Piacentino, C.; Votta, B.; Capello, E.; Mancardi, G.L.; Mutani, R.; Giordana, M.T.; Cavalla, P. Altered glutamate reuptake in relapsing-remitting and secondary progressive multiple sclerosis cortex: Correlation with microglia infiltration, demyelination, and neuronal and synaptic damage. J. Neuropathol. Exp. Neurol. 2007, 66, 732-739. [CrossRef] [PubMed]

68. Swartz, K.J.; During, M.J.; Freese, A.; Beal, M.F. Cerebral synthesis and release of kynurenic acid: An endogenous antagonist of excitatory amino acid receptors. J. Neurosci. 1990, 10, 2965-2973. [CrossRef] [PubMed]

69. Hilmas, C.; Pereira, E.F.; Alkondon, M.; Rassoulpour, A.; Schwarcz, R.; Albuquerque, E.X. The brain metabolite kynurenic acid inhibits alpha7 nicotinic receptor activity and increases non-alpha7 nicotinic receptor expression: Physiopathological implications. J. Neurosci. 2001, 21, 7463-7473. [CrossRef]

70. Flores-Barrera, E.; Thomases, D.R.; Cass, D.K.; Bhandari, A.; Schwarcz, R.; Bruno, J.P.; Tseng, K.Y. Preferential disruption of prefrontal GABAergic function by nanomolar concentrations of the $\alpha 7 \mathrm{nACh}$ negative modulator Kynurenic Acid. J. Neurosci. 2017, 37, 7921-7929. [CrossRef] 
71. Linderholm, K.R.; Andersson, A.; Olsson, S.; Olsson, E.; Snodgrass, R.; Engberg, G.; Erhardt, S. Activation of rat ventral tegmental area dopamine neurons by endogenous kynurenic acid: A pharmacological analysis. Neuropharmacology 2007, 53, 918-924. [CrossRef]

72. Wichers, M.C.; Koek, G.H.; Robaeys, G.; Verkerk, R.; Scharpé, S.; Maes, M. IDO and interferon-alpha-induced depressive symptoms: A shift in hypothesis from tryptophan depletion to neurotoxicity. Mol. Psychiatry 2005, 10, 538-544. [CrossRef]

73. Raison, C.L.; Dantzer, R.; Kelley, K.W.; Lawson, M.A.; Woolwine, B.J.; Vogt, G.; Spivey, J.R.; Saito, K.; Miller, A.H. CSF concentrations of brain tryptophan and kynurenines during immune stimulation with IFN-alpha: Relationship to CNS immune responses and depression. Mol. Psychiatry 2010, 15, $393-403$. [CrossRef] [PubMed]

74. Schwamborn, R.; Brown, E.; Haase, J. Elevation of cortical serotonin transporter activity upon peripheral immune challenge is regulated independently of p38 mitogen-activated protein kinase activation and transporter phosphorylation. J. Neurochem. 2016, 137, 423-435. [CrossRef] [PubMed]

75. Zhao, R.; Wang, S.; Huang, Z.; Zhang, L.; Yang, X.; Bai, X.; Zhou, D.; Qin, Z.; Du, G. Lipopolysaccharide induced serotonin transporter up-regulation involves pkg-i and p38mapk activation partially through a3 adenosine receptor. Biosci. Trends 2015, 9, 367-376. [CrossRef] [PubMed]

76. Tsao, C.W.; Lin, Y.S.; Cheng, J.T.; Lin, C.F.; Wu, H.T.; Wu, S.R.; Tsai, W.H. Interferon-alpha- induced serotonin uptake in Jurkat $\mathrm{T}$ cells via mitogen-activated protein kinase and transcriptional regulation of the serotonin transporter. J. Psychopharmacol. 2008, 22, 753-760. [CrossRef] [PubMed]

77. Haase, J.; Brown, E. Integrating the monoamine, neurotrophin and cytokine hypotheses of depression-A central role for the serotonin transporter? Pharmacol. Ther. 2015, 147, 1-11. [CrossRef] [PubMed]

78. Zhu, C.B.; Blakely, R.D.; Hewlett, W.A. The proinflammatory cytokines interleukin-1beta and tumor necrosis factor-alpha activate serotonin transporters. Neuropsychopharmacology 2006, 31, 2121-2131. [CrossRef]

79. Zhu, C.B.; Lindler, K.M.; Owens, A.W.; Daws, L.C.; Blakely, R.D.; Hewlett, W.A. Interleukin-1 receptor activation by systemic lipopolysaccharide induces behavioral despair linked to MAPK regulation of CNS serotonin transporters. Neuropsychopharmacology 2010, 35, 2510-2520.34. [CrossRef] [PubMed]

80. Zhu, C.B.; Hewlett, W.A.; Feoktistov, I.; Biaggioni, I.; Blakely, R.D. Adenosine receptor, protein kinase, G.; and p38 mitogen-activated protein kinase-dependent up-regulation of serotonin transporters involves both transporter trafficking and activation. Mol. Pharmacol. 2004, 65, 1462-1474. [CrossRef]

81. Zhu, C.B.; Carneiro, A.M.; Dostmann, W.R.; Hewlett, W.A.; Blakely, R.D. P38 MAPK activation elevates serotonin transport activity via a trafficking-independent, protein phosphatase 2a-dependent process. J. Biol. Chem. 2005, 280, 15649-15658. [CrossRef]

82. Zhu, C.B.; Steiner, J.A.; Munn, J.L.; Daws, L.C.; Hewlett, W.A.; Blakely, R.D. Rapid stimulation of presynaptic serotonin transport by A(3) adenosine receptors. J. Pharmacol. Exp. Ther. 2007, 322, 332-340. [CrossRef]

83. Morón, J.A.; Zakharova, I.; Ferrer, J.V.; Merrill, G.A.; Hope, B.; Lafer, E.M.; Lin, Z.C.; Wang, J.B.; Javitch, J.A.; Galli, A.; et al. Mitogen-activated protein kinase regulates dopamine transporter surface expression and dopamine transport capacity. J. Neurosci. 2003, 23, 8480-8488. [CrossRef] [PubMed]

84. Krishnadas, R.; Nicol, A.; Sassarini, J.; Puri, N.; Burden, A.D.; Leman, J.; Combet, E.; Pimlott, S.; Hadley, D.; McInnes, I.B.; et al. Circulating tumour necrosis factor is highly correlated with brainstem serotonin transporter availability in humans. Brain Behav. Immun. 2016, 51, 29-38. [CrossRef]

85. Korte-Bouws, G.A.H.; van Heesch, F.; Westphal, K.G.C.; Ankersmit, L.M.J.; van Oosten, E.M.; Güntürkün, O.; Korte, S.M. Bacterial Lipopolysaccharide Increases Serotonin Metabolism in Both Medial Prefrontal Cortex and Nucleus Accumbens in Male Wild Type Rats, but Not in Serotonin Transporter Knockout Rats. Pharmaceuticals 2018, 11, 66. [CrossRef]

86. Weinberger, J.F.; Raison, C.L.; Rye, D.B.; Montague, A.R.; Woolwine, B.J.; Felger, J.C.; Haroon, E.; Miller, A.H. Inhibition of tumor necrosis factor improves sleep continuity in patients with treatment resistant depression and high inflammation. Brain Behav. Immun. 2015, 47, 193-200. [CrossRef] [PubMed]

87. Raison, C.L.; Rutherford, R.E.; Woolwine, B.J.; Shuo, C.; Schettler, P.; Drake, D.F.; Haroon, E.; Miller, A.H. A randomized controlled trial of the tumor necrosis factor antagonist infliximab for treatment-resistant depression: The role of baseline inflammatory biomarkers. JAMA Psychiatry 2013, 70, 31-41. [CrossRef] [PubMed]

88. Mangge, H.; Becker, K.; Fuchs, D.; Gostner, J.M. Antioxidants, inflammation and cardiovascular disease. World J. Cardiol. 2014, 6, 462-477. 
89. Murr, C.; Winklhofer-Roob, B.M.; Schroecksnadel, K.; Maritschnegg, M.; Mangge, H.; Böhm, B.O.; Winkelmann, B.R.; März, W.; Fuchs, D. Inverse association between serum concentrations of neopterin and antioxidants in patients with and without angiographic coronary artery disease. Atherosclerosis 2009, 202, 543-549. [CrossRef]

90. McCarty, M.F. Supplementation with Phycocyanobilin, Citrulline, Taurine, and Supranutritional Doses of Folic Acid and Biotin-Potential for Preventing or Slowing the Progression of Diabetic Complications. Healthcare 2017, 5, 15. [CrossRef]

91. Miller, A.L. The methylation, neurotransmitter, and antioxidant connections between folate and depression. Altern. Med Rev. 2008, 13, 216-226.

92. Papakostas, G.I.; Shelton, R.C.; Zajecka, J.M.; Etemad, B.; Rickels, K.; Clain, A.; Baer, L.; Dalton, E.D.; Sacco, G.R.; Schoenfeld, D.; et al. L-methylfolate as adjunctive therapy for SSRI-resistant major depression: Results of two randomized, double-blind, parallel-sequential trials. Am. J. Psychiatry 2012, 169, 1267-1274. [CrossRef]

93. Popoli, M.; Yan, Z.; McEwen, B.S.; Sanacora, G. The stressed synapse: The impact of stress and glucocorticoids on glutamate transmission. Nat. Rev. Neurosci. 2011, 13, 22-37. [CrossRef] [PubMed]

94. Duman, R.S.; Monteggia, L.M. A neurotrophic model for stress-related mooddisorders. Biol. Psychiatry 2006, 59, 1116-1127. [CrossRef]

95. McEwen, B.S.; Bowles, N.P.; Gray, J.D.; Hill, M.N.; Hunter, R.G.; Karatsoreos, I.N.; Nasca, C. Mechanisms of stress in the brain. Nat. Neurosci. 2015, 18, 1353-1363. [CrossRef] [PubMed]

96. Nasca, C.; Xenos, D.; Barone, Y.; Caruso, A.; Scaccianoce, S.; Matrisciano, F.; Battaglia, G.; Mathé, A.A.; Pittaluga, A.; Lionetto, L.; et al. L-acetylcarnitine causes rapid antidepressant effects through the epigenetic induction of mGlu2 receptors. Proc. Natl. Acad. Sci. USA 2013, 110, 4804-4809. [CrossRef] [PubMed]

97. Bigio, B.; Mathé, A.A.; Sousa, V.C.; Zelli, D.; Svenningsson, P.; McEwen, B.S.; Nasca, C. Epigenetics and energetics in ventral hippocampus mediate rapid antidepressant action: Implications for treatment resistance. Proc. Natl. Acad. Sci. USA 2016, 113, 7906-7911. [CrossRef] [PubMed]

98. Nasca, C.; Bigio, B.; Zelli, D.; de Angelis, P.; Lau, T.; Okamoto, M.; Soya, H.; Ni, J.; Brichta, L.; Greengard, P.; et al. Role of the astroglial glutamate exchanger $\mathrm{xCT}$ in ventral hippocampus in resilience to stress. Neuron 2017, 96, 402-413. [CrossRef] [PubMed]

99. Nasca, C.; Bigio, B.; Lee, F.S.; Young, S.P.; Kautz, M.M.; Albright, A.; Beasley, J.; Millington, D.S.; Mathé, A.A.; Kocsis, J.H.; et al. Acetyl-L-carnitine deficiency in patients with major depressive disorder. Proc. Natl. Acad. Sci. USA 2018, 115, 8627-8632. [CrossRef] [PubMed]

100. Maalouf, M.; Sullivan, P.G.; Davis, L.; Kim, D.Y.; Rho, J.M. Ketones inhibit mitochondrial production of reactive oxygen species production following glutamate excitotoxicity by increasing NADH oxidation. Neuroscience 2007, 145, 256-264. [CrossRef]

101. Brietzke, E.; Mansur, R.B.; Subramaniapillai, M.; Balanzá-Martínez, V.; Vinberg, M.; González-Pinto, A.; Rosenblat, J.D.; Ho, R.; McIntyre, R.S. Ketogenic diet as a metabolic therapy for mood disorders: Evidence and developments. Neurosci. Biobehav. Rev. 2018, 94, 11-16. [CrossRef]

102. Consolaro, A.; Negro, G.; Chiara Gallo, M.; Bracciolini, G.; Ferrari, C.; Schiappapietra, B.; Pistorio, A.; Bovis, F.; Ruperto, N.; Martini, A.; et al. Defining criteria for disease activity states in nonsystemic juvenile idiopathic arthritis based on a three-variable juvenile arthritis disease activity score. Arthritis Care Res. 2014, 66, 1703-1709. [CrossRef]

103. Swart, J.F.; van Dijkhuizen, E.H.P.; Wulffraat, N.M.; de Roock, S. Clinical Juvenile Arthritis Disease Activity Score proves to be a useful tool in treat-to-target therapy in juvenile idiopathic arthritis. Ann. Rheum. Dis. 2018, 77, 336-342. [CrossRef] [PubMed]

(C) 2019 by the authors. Licensee MDPI, Basel, Switzerland. This article is an open access article distributed under the terms and conditions of the Creative Commons Attribution (CC BY) license (http:/ / creativecommons.org/licenses/by/4.0/). 